\title{
Presentación
}

\section{Sufragio femenino en América Latina: alianzas nacionalistas y políticas transnacionales}

\author{
Women's Suffrage in Latin America: National Alliances and \\ Transnational Politics
}

El sufragismo fue, sin duda, el movimiento que permitió nuclear los esfuerzos tanto individuales como colectivos en procura de mejoras sociales y políticas para la mujer. En torno a la consigna por el derecho al voto se articularon demandas por un pacto social equitativo y en defensa de los derechos humanos a escala global. Sin embargo, también fue un movimiento que enfrentó a grupos y organizaciones lideradas por mujeres que se alinearon a favor o en contra de movilizarse en pos del reconocimiento de los derechos políticos para su género. Para las latinoamericanas, diferenciarse del sufragismo combatiente de las británicas y del feminismo de corte imperialista proveniente de Estados Unidos conllevaba el desafío de elaborar alianzas que no implicaran subordinación, además de establecer liderazgos que movilizaran el cuerpo político hacia procesos democratizadores.

El logro del voto femenino en América Latina se vio favorecido por la larga tradición de clubes femeninos, organizaciones antiesclavistas y grupos vinculados al feminismo que intervinieron en la opinión pública a través de la prensa, el arte y la literatura. También influyó en este proceso el creciente liderazgo de algunas mujeres profesionales e intelectuales, como Alicia Moreau de Justo en Argentina, Paulina Luisi en Uruguay 
o Zoila Aurora Cáceres en el Perú, quienes formaron alianzas con representantes de las clases privilegiadas y con miembros de agrupaciones anarcosocialistas y obreras. En ese sentido, los movimientos sufragistas en América Latina representaron un salto sustancial respecto de los debates iniciados en el siglo XIX, que se habían concentrado mayormente en temas como la maternidad y la educación femenina y no habían elaborado proyectos emancipatorios ni propulsado la participación política de la mujer a través del voto.

Además, la contienda que enfrentó durante largas décadas a diversos grupos en torno a la ampliación del sufragio supuso un cambio en la categoría de ciudadano y una nueva forma de comprender las relaciones entre Estado y sociedad civil. Esta transformación fue encauzada por muy variados actores sociales, cuyas intervenciones en la consecución o retraso del voto femenino varía de país en país según las coyunturas económicas, políticas, sociales y culturales de los procesos modernizadores, el tipo de sistema político, la influencia del liberalismo, la emergencia de partidos políticos y los movimientos de mujeres. La lucha por la aplicación del derecho al voto se desarrolló a pesar, y en oportunidades a contrapelo, de diversas instancias de crisis democrática, en las que la expansión del nazismo y la instauración de regímenes de corte autoritario amenazaban la región, articulándose con los procesos colonizadores e imperialistas. Por esta razón, las batallas se dieron simultáneamente en ámbitos locales, nacionales, regionales y globales.

En un primer momento de la historia del sufragismo femenino, se puede hablar de dos caminos principales. Uno es el que reconoce el sufragio femenino casi de forma simultánea al masculino, en un contexto de lucha amplia por la democratización. El otro, que se da en la mayoría de los países, es el que admite el voto femenino de manera tardía, ya sea gradualmente -haciendo, por ejemplo, que las mujeres voten primero en elecciones locales- o limitando el ejercicio cívico a un grupo particular de mujeres, como el que se les dio a aquellas que ejercían labores similares a las de los varones. Comparando las experiencias por países, pesaron también los cálculos estratégicos de las élites locales en la decisión de reconocer el derecho al voto a ciertos grupos de mujeres. En general, los partidos conservadores impulsaron con mayor fuerza el sufragio femenino, ya que creían beneficiarse del ingreso de este electorado. Por otra parte, los partidos de base popular generalmente evitaron tomar 
una posición ante el sufragio femenino, pues, reafirmando la misoginia de algunos de los primeros ideólogos de los movimientos obreros, veían en el voto de las mujeres una amenaza al proyecto socialista.

En una segunda etapa, ya entrado el siglo XX, el factor principal para reconocer el voto a las mujeres estuvo marcado por la presión ejercida por organismos internacionales y por las redes diplomáticas. En 1933, la Séptima Conferencia Internacional Americana en Montevideo marcó un momento decisivo en las relaciones interamericanas, ya que allí se dio a conocer el Informe de la Comisión Interamericana de Mujeres sobre la igualdad política y civil de la mujer. Como antecedente de este reclamo pueden incluirse también los cuatro congresos de mujeres a nivel internacional que se desarrollaron en Argentina (1910), Chile (1923), Perú (1924) y Colombia (1930). Así, el sufragismo fue consolidando un doble eje, cuyo poder simbólico se extiende más allá de su enclave referencial y nacional, proyectándose como un movimiento transnacional potenciado por el deseo de imaginar una sociedad más justa, solidaria y equitativa. Alrededor del reclamo por el derecho al voto se organizaron alianzas y redes internacionales que pusieron en diálogo a una serie diversa de figuras del mundo de la política, el arte y las letras. Estas comenzaron a pronunciarse y a militar en temáticas relacionadas con los derechos femeninos en la esfera política internacional. Por último, el período que va de 1920 a 1960, décadas en las que progresivamente se reconoció el derecho al voto de la mujer en América Latina, estuvo influenciado por la fuerte crisis política internacional. Las mujeres se colocan al frente de este escenario de transformaciones múltiples y las traducen en oportunidades para la ampliación de sus derechos.

A partir del trabajo pionero de Ida Blom en la década de 1980 y el reconocimiento del voto como agente de poder en sistemas democráticos, una serie de investigaciones se han enfocado en destacar el rol del género en las dinámicas de exclusión política y discriminación social. Asunción Lavrin, en su estudio pionero Women, Feminism, and Social Change in Argentina, Chile, and Uruguay 1890-1940 (1995), revisa el sufragismo en estos países enfatizando sus puntos de contacto. Teresa Valdés, en su trabajo De lo social a lo politico: la acción de las mujeres latinoamericanas (2000), señala el valor político de la acción colectiva desarrollada por mujeres desde la época de la colonia, identificando la lucha por la ciudadanía con las demandas de las mujeres en recla- 
mo de igualdad. Por su parte, Maxine Molyneux, en Movimiento de mujeres en América Latina: estudio teórico comparado (2003), define la realidad de los países latinoamericanos como hostiles a los discursos de igualdad, debido a la influencia del catolicismo y las características del liberalismo. Según Molyneux, estas cuestiones llevaron a desarrollar un discurso feminista basado en la diferencia, destacando cómo las virtudes femeninas tradicionales fueron usadas para exigir plena participación política. Así mismo, Mary Nash, en Mujeres en el mundo: historia, retos y movimientos (2004), plantea que es necesario considerar los marcos institucionales para entender el fenómeno, ya que cuestiones como el liberalismo o el peso de la Iglesia católica fueron relevantes en dificultar o acelerar el reclamo de las mujeres por la igualdad de derechos. La publicación más reciente de Adriana Valobra-colaboradora también en este número-, Ciudadanía política de las mujeres en Argentina (2018) ofrece un panorama de las luchas, figuras y debates en torno a la ciudadanía política de las mujeres en el siglo XX, con claves útiles para el presente. Su trabajo no solo abarca la historia del movimiento sufragista en Argentina sino que también se extiende a los períodos posteriores al logro del voto femenino en el país, atendiendo a cuestiones de representación política de las mujeres pre y postdictadura, en un presente donde el feminismo vuelve a tener una centralidad en los debates políticos del país y la región.

Otros estudios recientes, entre los que se encuentran Feminism for the Americas: The Making of an International Human Rights Movement (2019), de Katherine Marino, y Vanguard: How Black Women Broke Barriers, Won the Vote, and Insisted on Equality for All (2020), de Martha S. Jones, han evidenciado la necesidad de explorar los diversos movimientos sufragistas en las Américas desde perspectivas que reconozcan su heterogeneidad sin pasar por alto los múltiples engranajes en que lo local, regional y nacional se articularon con reivindicaciones por justicia social a nivel global. El libro de Marino, reseñado en este volumen, señala el protagonismo del feminismo latinoamericano en el proceso democratizador de la región. El trabajo de Jones, por su parte, reclama atención hacia otras formas de entender y construir poder político, señalando cómo las mujeres afrodescendientes ubicaron la lucha por el derecho al voto en un proyecto mayor que articulaba los derechos civiles, la reforma social, la justicia civil y el derecho internacional. 
Los artículos aquí reunidos no buscan reescribir una historia político-legal del sufragio sino, más bien, analizar el impacto social y cultural del movimiento sufragista en América Latina y explorar su repercusión en otras dimensiones de los debates de género. Entendemos, entonces, que el sufragio funciona como un punto de partida que convoca otras cuestiones con resonancias locales, continentales y trasatlánticas, como, por ejemplo, las luchas obreras o los reclamos por una mayor participación de las mujeres en ámbitos como el educativo o el laboral. Por ello, cada estudio tiene como trasfondo una sociedad androcéntrica que excluyó a las mujeres de la participación política, social y cultural, y que fue interpelada por las propias mujeres desde los diversos lugares de enunciación que ocuparon, ya sea el hogar, la escuela, la prensa o la fábrica.

En el artículo que encabeza este volumen, Francesca Denegri nos propone recuperar la memoria historia de los que apropiadamente llama "sufragismos tempranos" en Perú, Argentina y España, poniéndolos en diálogo con otros movimientos y con el sufragismo británico. Alertando sobre el desafío que reviste el tema debido a la escasez de trabajos críticos y bibliográficos desde los que se debe partir, Denegri traza las conexiones y los desencuentros protagonizados por mujeres movilizadas en torno a la obtención de derechos políticos a principios del siglo XX. Los focos de irradiación del feminismo identificados por Denegri y su compleja relación con el sufragismo le permiten abordar el rol que los viajes, la literatura y la prensa jugaron en la construcción del activismo de mujeres que oscilaron entre el miedo a la masculinización y el deseo de apartarse del maternalismo hegemónico. Al reflexionar sobre la irrepresentabilidad de la sufragista como signo, el artículo invita a evitar que el legado de estas mujeres permanezca olvidado.

Inés Cuadro, en "Las redes intelectuales rioplatenses de la médica uruguaya Paulina Luisi: otra cara del internacionalismo feminista del Novecientos", revisa un aspecto que es constituyente del movimiento sufragista: el internacionalismo. A través del análisis de las redes conformadas por una de las figuras fundamentales del feminismo uruguayo, Paulina Luisi, Cuadro profundiza en la comprensión del fenómeno para el caso uruguayo y a la vez aporta elementos para una mirada amplia y transnacional. Su análisis plantea una crítica desde el feminismo a los acercamientos tradicionales de la historia política, a través de una lectura cuidadosa de las fuentes. Particularmente, Cuadro revisa cartas 
personales de Luisi, enfatizando el aporte de este género de escritura íntima al estudio de la historia de los fenómenos políticos.

Sonia Priscila Ticas, en tanto, plantea una valiosa revisión de las múltiples líneas de participación ciudadana salvadoreña, en las que las mujeres oscilaron entre elaborar alianzas internacionales para reclamar su pleno acceso a la esfera política y un "feminismo conciliador" durante períodos de inestabilidad y crisis democrática. Ticas traza un recorrido por las múltiples facetas que tuvieron que atravesar los movimientos de mujeres salvadoreńas desde la segunda década del siglo XX, cuando las protestas callejeras las exponían a ser cruelmente reprimidas a tiro de metralla, hasta los años cincuenta, momento en que la Constitución Política ratificó su derecho a participar en los comicios electorales. Alternando entre reclamos nacionalistas y la inserción de El Salvador en el debate internacional, mujeres de muy diversa extracción operaron por más de treinta ańos en la esfera pública reclamando mejoras en la educación, en la atención sanitaria y en el reconocimiento de derechos laborales, convirtiendo su lucha por el sufragio en un elemento más de un vasto proceso de negociación de los derechos ciudadanos en Centroamérica.

Por su parte, el trabajo de Sofía Pachas Maceda, "Las chicas del cable en huelga. Feminismo Peruano Zoila Aurora Cáceres y el reclamo de las telefonistas (Lima, 1931)", es un claro ejemplo de que el impacto social del movimiento sufragista fue más allá del reclamo político puntual por el voto. El debate sobre el sufragio femenino dio vuelo también a reclamos laborales y civiles de diversa índole, que evidenciaban que las discusiones de género estaban a la orden del día tanto en el campo político como en el cultural. Pachas Maceda se detiene en la lucha que en 1931 encabezaron un grupo de mujeres telefonistas limeńas, para quienes la militante sufragista y escritora Zoila Aurora Cáceres resultó una figura clave para dar visibilidad y alcance al reclamo de mejores condiciones de trabajo. Las telefonistas sostuvieron una huelga que, en palabras de Pachas, desafió el statu quo de la sociedad peruana. Mientras que las mujeres en Perú aún continuaban sometidas al Código Civil del siglo anterior, sus necesidades diarias respondían a un presente en el que la mujer había diversificado sus roles y actividades. Los vínculos sociales e intelectuales de Cáceres -que no era simplemente la hija del héroe de la Guerra del Pacífico y posterior líder político, Andrés Avelino Cáceres, sino una reconocida escritora, feminista y agente cultural tanto en Latinoamérica 
como en Europa- lograron que el colectivo telefonista consiguiera una amplia cobertura en la prensa peruana. De esta manera, Pachas Maceda pone énfasis en las alianzas femeninas que, desde un comienzo, estuvieron en el corazón de la lucha sufragista. Así demuestra que la unión de esfuerzos multiplica los resultados: las telefonistas consiguen la atención de la clase política y los medios mientras que, estratégicamente, Zoila Aurora Cáceres también logra la continuidad política para un reclamo -el voto femenino- que aún no lograba la aprobación en el Congreso.

Finalmente, el trabajo de Adriana Valobra, "Elogio de la mujer que vota. El voto municipal femenino en Santa Fe, Argentina”, analiza el proceso que implicó la discusión sobre el sufragio femenino a nivel local en Argentina. Valobra plantea relevantes preguntas a un tema que, aunque desde una perspectiva de historia nacional se ha dado por resuelto, al considerar las especificidades, se develan aspectos no explorados del fenómeno. Así, el análisis establecido desde la teoría feminista elabora nuevas preguntas, estimulando una mejor comprensión de la cultura política en clave de género y aportando explicaciones que muestran trasfondos desconocidos. Valobra nos invita a pensar el voto municipal en relación con las intersecciones de género, clase y nacionalidad.

Este número especial también incluye una sección de notas en las que damos a conocer reflexiones, traducciones, entrevistas y textos históricos vinculados al movimiento sufragista en nuestro continente.

Por ejemplo, la conflictiva relación entre derechos políticos para la mujer y derechos fundamentales para el hombre latinoamericano en el período posterior a la Segunda Guerra Mundial es abordada por Teresa Cristina de Novaes a través de la exploración de documentos que demuestran el fortalecimiento del posicionamiento diplomático de Brasil en la región y la estratégica alianza entre países que formaron parte de la Comisión Jurídica Interamericana. Novaes recoge aspectos poco explorados por estudios sobre el sufragio femenino en la región, como una forma de convocar a nuevas exploraciones que contribuyan a un mejor conocimiento del impacto político y cultural que significó el acceso al voto para la mujer.

Luego, en la nota "Puerto Rican Women's Struggle for Suffrage”, Margaret Power plantea revisar la lucha por el sufragio femenino en Puerto Rico a través de las nociones de soberanía nacional e imperialismo, que convirtieron a las puertorriqueńas en ciudadanas sin derecho al voto. 
Por su parte, Silvina Sartelli contribuye a esta sección con la traducción de dos fuentes valiosas en la tradición sufragista inglesa. La primera es una carta de Emmeline Pankhurst, líder de la Unión Social y Política de las Mujeres (1903), en la que se incita a las mujeres a tomar una militancia activa y agresiva, la cual fue motivo de varias tensiones entre los mismos grupos de mujeres en Inglaterra. La segunda es una vińeta antisufragio que, con tono satírico, ejemplifica algunos de los ataques y prejuicios más comunes que pesaban a comienzos del siglo XX en las mujeres que reclamaban su derecho al voto. En la misma línea de rescate de fuentes, la historiadora Paula Alonso recupera un texto con imágenes relevantes del movimiento sufragista en Argentina, publicado por Mundo Argentino en 1946, al mes siguiente de que el proyecto de ley sobre sufragio femenino fuera presentado por el peronismo y aprobado en el Senado de la nación. El artículo está firmado por Leonor Causa y lleva el título de "Qué harán las mujeres si llegan a gobernar". Se trata de un interesante documento que nos remite a la tensión entre sufragistas y peronismo y al intento de las primeras de historizar la lucha y "desperonizarla" frente al presente contexto nacional. La "genealogía" sufragista que propone Mundo Argentino es otra muestra del complejo entramado ideológico que implicó el reclamo por un mismo derecho.

Por último, Claudia Montero ofrece una entrevista a Joyce Contreras Villalobos, doctora en Literatura por la Pontificia Universidad Católica de Valparaíso, acerca de su proyecto editorial La Hoguera. En plena pandemia, Contreras lanzó este sello editorial que tiene como finalidad la recuperación de textos de autoras desconocidas o invisibilizadas en el campo literario o periodístico chileno. En la entrevista, Contreras hace mención a la primera publicación de su sello en 2020: Mis observaciones de Delie Rouge -seudónimo de la escritora Delia Rojas-, publicado originalmente en 1915, en el que la autora discute temáticas de género directamente vinculadas al clima sufragista y feminista de comienzos del siglo XX. Con este cierre, nuestro número reafirma la necesidad de historizar los movimientos feministas desde un presente con fuertes reflexiones en torno a las identidades y roles de género. Si el sufragio fue un reclamo aglutinador de esfuerzos políticos e intelectuales desde finales del siglo XIX, nuestro presente no está menos marcado por la presencia de reclamos e impulsos locales y globales para la ampliación de los derechos de las mujeres y las identidades no binarias. Seguimos reclamando acceso a derechos civiles y políticos y pidiendo por la auto- 
nomía y pluralidad de los cuerpos y las sexualidades. Hacerlo con una perspectiva histórica, que nos marque el camino recorrido, los logros conseguidos y las metas presentes y futuras, es una forma de reafirmar que estos son el resultado de esfuerzos colectivos que es preciso sostener día a día, en cada ámbito de nuestras vidas.

María Alejandra Aguilar Dornelles Universidad de Albany-SUNY, Estados Unidos http://orcid.org/0000-0002-9479-8775 maguilardornelle@fau.edu

\author{
VANesa Miseres \\ Universidad de Notre Dame, Estados Unidos \\ https://orcid.org/0000-0002-7093-9369 \\ vanesa.a.miseres.1@nd.edu
}

Claudia Montero Universidad de Valparaíso, Chile http://orcid.org/0000-0001-5209-0931 claudia.montero@uv.cl 